\title{
The Danish Hip Arthroscopy Registry: Registration Completeness and Patient Characteristics Between Responders and Non-Responders
}

This article was published in the following Dove Press journal: Clinical Epidemiology

\author{
Erik Poulsen (iD) \\ Bent Lund (D) ${ }^{2}$ \\ Ewa M Roos (iD) \\ 'Department of Sports Science and \\ Clinical Biomechanics, University of \\ Southern Denmark, Odense, Denmark; \\ ${ }^{2}$ Department of Orthopedic Surgery, \\ Horsens Regional Hospital, Horsens, \\ Denmark
}

Purpose: To report completeness of registered surgeries in the Danish hip arthroscopy registry (DHAR) and proportion of patients completing patient-reported outcome measures (PROMs) prior to surgery and at 1-year follow-up.

Patients and Methods: Completeness was determined as the number of surgeries registered in DHAR in comparison with the number of surgeries registered in the Danish National Patient Registry database (DNPR). The number of patients self-reporting pre-surgical PROMs was compared to the total number of surgeries registered in DHAR. Further, we evaluated potential differences in baseline characteristics between the groups of responders and non-responders at 1-year follow-up. Patient characteristics included age, sex, activity levels measured by the hip sports activity scale (HSAS), and PROMs (Copenhagen Hip and Groin Outcome Score, EQ-5D-3L and general hip status). Age was stratified in three groups $(<25,25-39, \geq 40)$.

Results: From February 2012 to September 2018, 5565 arthroscopic hip surgeries were registered in DNPR, and 4937 were registered in DHAR (89\%). The yearly rate of registrations in DHAR compared to DNPR increased from $77 \%$ in 2012 to $85 \%$ in 2018 and peaking in 2015 at $94 \%$. A total of 3294 DHAR-registered patients $(67 \%)$ had self-reported their presurgical outcome scores, and of those, 2886 (58\%) completed PROMs at 1-year follow-up. More males ( 45 vs $41 \%, \mathrm{p}=0.002)$ and individuals younger than 25 years of age $(24 \% \mathrm{vs}$ $18 \%, \mathrm{p}<0.001$ ) had not completed follow-up questionnaire. The PROM baseline scores of the responders at follow-up did not differ from the non-responders.

Conclusion: The proportion of arthroscopic hip surgeries registered in the Danish Hip Arthroscopy Registry and the proportion of self-reporting PROM scores have increased to acceptable levels, whereas the proportion of patients with follow-up data is comparably low. For further quality improvement, more attention should be given to patients completing PROMs, focusing on younger males and follow-up PROMs.

Keywords: database, hip arthroscopic surgery, epidemiology, data quality, Denmark

\section{Introduction}

Hip arthroscopy has, since its wider introduction at the beginning of this century, developed into a commonly offered surgery for individuals suffering from persistent hip and groin pain, predominantly for impingement type conditions and labral lesions. ${ }^{1}$ In recent year, several countries have seen large increases in the numbers
Center for Muscle and Joint Health,

Department of Sports Science and

Clinical Biomechanics Campusvej 55,

Odense M DK-5230, Denmark

Tel +4565504532

Email epoulsen@health.sdu.dk 
of performed hip arthroscopic surgeries ${ }^{2-5}$ and the procedure has been labeled as one of the fastest-growing specialties in orthopedic surgery. ${ }^{6}$

For a range of orthopedic specialties, national and regional clinical registries have been developed to monitor clinical quality, patient safety and for measuring clinical effectiveness. $^{7-9}$ For the same purpose, the Danish Hip Arthroscopy Registry (DHAR) was initiated in 2011, and in February 2012, the first patients were entered in the database. ${ }^{10}$ Registration is voluntary and collects clinical, peri-surgical and patient-reported information. Currently, all public and private orthopedic hospitals/centers in Denmark performing hip arthroscopies participate and provide data (15 hospitals/centers at the time of writing). ${ }^{11}$

In comparison with other study designs like clinical trials, registries are able to collect large amounts of data at relatively low cost. ${ }^{12}$ However, in order to ensure usefulness and data quality, different parameters should be evaluated. ${ }^{13}$ Knowledge of registry completeness is essential for evaluating possible selection bias and secure generalizability. ${ }^{13}$ For procedural registries like DHAR, this relates to the number of hip arthroscopies (procedures) recorded in comparison to the total number of procedures performed for a given area and period. ${ }^{14}$ When registries include measures of clinical effectiveness of the procedure(s), it is today common practice to include relevant and valid general and disease-specific patient-reported outcomes measures (PROMs), ${ }^{7,15-17}$ at presurgery and at mid- to long-term follow-up (2-10 years). Completeness here can be assessed as the number of patients recording PROMs and the number of patients completing follow-up PROMs. To ensure the quality and usefulness of the follow-up data, different relevant patient characteristics including the PROMs can be evaluated for possible differences between responders and non-responders. ${ }^{7,16}$

The purpose of this study was to examine the completeness of hip arthroscopies registered in DHAR compared to registrations in the Danish National Patient Registry, evaluate the proportion of patients completing patientreported outcomes in DHAR and examine differences in relevant patient outcomes between responders and nonresponders at follow-up.

\section{Materials and Methods}

\section{Databases}

\section{The Danish Hip Arthroscopy Registry (DHAR)}

The DHAR is a secure web-based database prospectively collecting pre-surgical clinical/radiological, peri-surgical and pre-surgical patient-reported data through standardized forms. ${ }^{10,18}$ In connection with each surgery, the surgeon records the clinical, imaging and detailed surgical data. Perisurgical information includes previous hip surgery, reoperations, duration of surgery, traction time, labrum and cartilage lesions, specific surgical technique characteristics and perioperative complications. Prior to the surgery, the patient receives access to the web-based patient questionnaire at the outpatient clinic. The patient completes information regarding consent, operating hospital, email address for future follow-ups, and validated PROMs: Copenhagen Hip and Groin Outcome Score (HAGOS), the International Hip Outcome Tool short version (iHOT12), both scoring 0-100 worst to best, the EQ-5D-3L and various pain scales in the form of visual analog scales. ${ }^{19-21}$ Activity levels are assessed by the Hip Sports Activity Scale (HSAS). ${ }^{22}$ Individual patient entries are automated so each individual question requires an entry prior to progression to the following question. Registry organization and a complete list of clinical, surgical and patient-related variables including baseline scores and arthroscopic revision surgeries are previously published. $^{18}$ Follow-up data include 1-year postsurgical data and validated patient-reported outcomes at 1-year, 2-year, 5-year and 10-year. Patients receive an automated e-mail notion from the registry at the relevant follow-ups and reminders are sent twice for each follow-up.

\section{The Danish National Patient Registry}

In Denmark, each hospital contact for public and private hospitals is registered in the Danish National Patient Registry (DNPR) with a unique record number including information related to patient demographics, date and time of admission/discharge, diagnosis, operation, hospital and department. $^{23}$ Each unique record number is related to the individual patient through a personal identification number (CPR) unique to each individual residing in Denmark. ${ }^{24}$ Diagnosis codes are registered according to the International Classification of Diseases (ICD-10) and intervention codes (eg operations) are classified according to the Nordic Classification of Surgical Procedures (NCSP).

\section{Study Population}

We extracted record numbers for all individuals having received hip arthroscopy during the period March 1st, 2012-September 1st, 2018 from the DHAR and DNPR. From DNPR, hip arthroscopy procedures were identified by surgical codes for hip arthroscopies recommended by 
the Danish National Board of Health. ${ }^{25,26}$ In addition, an e-mail survey was sent to surgeons performing hip arthroscopy in Denmark querying for additional surgical codes used for hip arthroscopy. We included records when a minimum of one surgical code (of the list recommended by the National Board of Health) was registered as either primary or secondary procedure. For each record number, additional data were retrieved regarding age, sex, diagnosis and health care region of the hospital. The specific surgical codes used for identification are listed in Supplementary Tables 1 and $\underline{2}$.

\section{Completeness of Hip Arthroscopies Registered in DHAR}

For the study period, each unique personal identification number registered in DNPR was cross-referenced with the matching number in DHAR. An entry in both DNPR and DHAR was identified as a match and completeness was identified as the percentage of total numbers of matchings versus the total number of unique registrations in DNPR. Patients having several hip arthroscopic surgeries were identified by the personal identification number matching more than one unique hospital record number on different dates. Stratification was performed for age $(<25,25-39$, $\geq 40$ ) and at regional health care level (five separate geographical regions of Denmark).

\section{Completeness of Patient-Entered Outcomes Registered in DHAR}

The completeness of patients registering pre-surgical baseline data and PROMs in DHAR was analyzed by comparing the number of patients (individual personal identification numbers) entering pre-surgical data in DHAR versus the total number of patients registered in DHAR (registered by the surgeons). A patient-entered dataset was included when a minimum of one of the PROMs was completed.

\section{Differences Between Responders and Non-Responders}

To investigate if specific characteristics were related to response rates at follow-up, we compared pre-surgical baseline patient demographics and patient-reported outcome measures between the groups of patients completing the 1-year follow-up and patients not completing the 1-year follow-up (ie responders versus non-responders). Patient characteristics were age, sex, activity level measured by the Hip Sports Activity Scale (HSAS) and hospital performing the surgery. Patient-reported outcomes were HAGOS, EQ-5D-3L and VAS general hip status. One-year follow-up and response rates were reported for all six HAGOS subscales: Pain, Symptoms, Function in daily living (ADL), Function in sports and recreation (Sports/rec), Participation in Physical Activity (PA) and hip and/or groin-related quality of life (QOL).

\section{Statistics and Data Analysis}

Registration Completeness of Hip Arthroscopies and Patient Reporting in DHAR

Completeness of registrations in DHAR vs DNPR and patients reporting in DHAR vs surgeries registered in DHAR is presented as numbers and percentages by year.

\section{Differences Between Responders and Non-Responders}

For age, sex, the six HAGOS subscales, EQ-5D-3L, HSAS and VAS scales, responders versus non-responders at 1-year follow-up were analyzed by comparing pre-surgical mean scores between the group of responders versus the group of non-responders using the chi-squared test for categorical data or Student's $t$-test for numerical data (including 95\% confidence intervals). Age was stratified into three groups $(<25$, 25-39, $\geq 40$ ), ${ }^{18}$ HSAS into sedentary (HSAS $=1$ ), recreational (HSAS $=2-4$ ), competitive (HSAS $=5-7$ ) and elite $(\text { HSAS }=8 \text { and } 9)^{22}$ and hospitals into the five geographical regions of Denmark (North Jutland, Mid Jutland, Southern Denmark, Capitol Region and Zealand). The description of HSAS categories is listed in Supplementary Table 3. All data analyses were performed using STATA version 15 (StataCorp, College Station, TX, USA).

All four databases (DNPR, DHAR pre-surgical clinical, DHAR pre-surgical PROM, and DHAR 1-year follow-up) were cleaned and screened for double entries prior to analyses. Cleaning referring to excluding data entries without a personal identification number, entries with personal identification number but without any PROM entries and entries not consenting to provide data for DHAR. Double entries were identified as identical personal identification numbers registered on the same day with identical pre-surgical values.

\section{Sensitivity Analysis of Surgical Codes Registered in DNPR}

From our e-mail survey to surgeons, we identified additional surgical codes used by surgeons to register hip arthroscopies in DNPR from the codes recommended by the Danish National Board of Health (Supplementary Tables 1 and 2). Therefore, we performed a sensitivity analysis of these 
additional codes when used as primary surgical procedure code but still including the Danish National Board of Health recommended codes as secondary codes.

\section{Results}

\section{DHAR Completeness versus DNPR}

From February 2012 to September 2018, a total of 4937 (88.4\%) hip arthroscopic surgeries were registered in DHAR and 5565 in DNPR. Of the 4937 registered in DHAR, $23(0.4 \%)$ were not registered in DNPR. Of the 4.937 surgeries registered in DHAR, 709 (14.4\%) were classified by the surgeons as reoperations of the same hip. The number of registered surgeries in DHAR and DNPR including completeness by percent for each year is presented in Table 1 . Throughout the period completeness increased from $77 \%$ for the first year of 2012 to $85 \%$ for the first 8 months of 2018. The completeness rate was at its highest in 2015 reaching 94\%. Patient demographics (mean age at surgery and percentage of females) for patients registered in DHAR and DNPR are reported in Table 2. There was an annual increase in mean age from 34 to 40 observed in DHAR due to fewer hip arthroscopies performed on patients $<20$ years from 2012 to 2018 (2012 $=73,2013=113,2014=102,2015=89,2016=59,2017$ $=32$ and $2018=11$ ).

\section{Registration Completeness of Patients}

\section{Entered Outcomes}

As of September 2018, 3294 patients (67\%) had registered their pre-surgical outcome measures in DHAR. Additional 80 entries (2.4\%) did not have personal identification number entered or did not have any PROM data registered. Consent to provide PROM data was not given for 48 patients (1.4\%). The yearly completeness rate of patients reporting in DHAR compared to operated and registered patients by the surgeons is presented in Table 3. The rate improved from $56 \%$ in 2012 to $90 \%$ in 2018 . Baseline patient-reported outcome scores are presented in Table 4.

\section{Differences Between Responders and Non-Responders}

Of the 4937 arthroscopic hip surgeries registered in DHAR, 2886 patients (58.5\%) had registered their 1-year follow-up questionnaire. In addition to the 2886 patients, 303 patients $(10.9 \%)$ had registered their personal identification number at the 1-year follow-up but did not register any PROM values. Of the 2886 included, 59\% were females versus $41 \%$ males and of the responders versus non-responders, $59 \%$ females were responders versus $41 \%$

Table I Completeness of Registrations in DHAR vs DNPR, 2012-2018

\begin{tabular}{|l|l|l|l|l|l|l|l|}
\hline & 2012 & 2013 & 2014 & 2015 & 2016 & 2017 & $\mathbf{2 0 1 8}$ \\
\hline $\begin{array}{l}\text { Number of hip arthroscopies registered in } \\
\text { DHAR }\end{array}$ & $398^{*}$ & 643 & 947 & 885 & 803 & 757 & $504^{* *}$ \\
\hline $\begin{array}{l}\text { Number of hip arthroscopies registered in } \\
\text { DNPR }\end{array}$ & $517^{*}$ & 738 & 1059 & 940 & 860 & 880 & $594^{* *}$ \\
\hline $\begin{array}{l}\text { Completeness (DHAR/DNPR) \% } \\
(95 \% \text { confidence interval) }\end{array}$ & $\begin{array}{l}77.0 \\
(73.4-80.6)\end{array}$ & $\begin{array}{l}87.1 \\
(84.7-89.5)\end{array}$ & $\begin{array}{l}89.4 \\
(87.6-91.2)\end{array}$ & $\begin{array}{l}94.1 \\
(92.5-95.6)\end{array}$ & $\begin{array}{l}93.4 \\
(91.7-95.1)\end{array}$ & $\begin{array}{l}86.0 \\
(83.7-88.3)\end{array}$ & $\begin{array}{l}84.9 \\
(82.0-87.8)\end{array}$ \\
\hline
\end{tabular}

Notes: *From February Ist 2012 when registration in DHAR commenced, **until September Ist 2018.

Abbreviations: DHAR, the Danish hip arthroscopy registry; DNPR, the Danish national patient registry.

Table 2 Characteristics of Patients Registered in DHAR and DNPR, 20I2-2018

\begin{tabular}{|l|l|l|l|l|l|l|l|}
\hline & $\mathbf{2 0 1 2}$ & $\mathbf{2 0 1 3}$ & $\mathbf{2 0 1 4}$ & $\mathbf{2 0 1 5}$ & $\mathbf{2 0 1 6}$ & $\mathbf{2 0 1 7}$ & $\mathbf{2 0 1 8}$ \\
\hline Age at surgery & & & & & & \\
Hip registry, DHAR (mean, SD) & $33.9(12.5)$ & $34.7(12.8)$ & $36.0(12.5)$ & $37.3(12.6)$ & $38.8(12.5)$ & $38.8(12.1)$ & $39.8(12.2)$ \\
National registry, DNPR (mean, SD) & $38.3(12.6)$ & $37.1(12.5)$ & $37.0(12.5)$ & $37,2(12.5)$ & $37.0(12.4)$ & $37.4(12.7)$ & $37.1(12.4)$ \\
\hline Sex, females & & & & & & & \\
Hip registry, DHAR, n (\%) & $234(59)$ & $385(60)$ & $542(57)$ & $496(56)$ & $446(55)$ & $446(59)$ & $284(56)$ \\
National registry, DNPR, n (\%) & $302(58)$ & $378(51)$ & $594(56)$ & $526(56)$ & $501(58)$ & $504(57)$ & $536(59)$ \\
\hline
\end{tabular}

Abbreviations: SD, standard deviation; DHAR, the Danish hip arthroscopy registry; DNPR, the Danish national patient registry; n, numbers. 
Table 3 Percentage of Patients Reporting Baseline Outcome Measures Compared to Total Number of Patients Registered in DHAR

\begin{tabular}{|l|l|l|l|l|l|l|l|}
\hline & $\mathbf{2 0 1 2}$ & $\mathbf{2 0 1 3}$ & $\mathbf{2 0 1 4}$ & $\mathbf{2 0 1 5}$ & $\mathbf{2 0 1 6}$ & $\mathbf{2 0 1 7}$ & $\mathbf{2 0 1 8}$ \\
\hline Number of patients reporting in DHAR & 224 & 429 & 534 & 570 & 481 & 605 & 451 \\
\hline Number of surgeries registered in DHAR & 398 & 643 & 947 & 885 & 804 & 757 & 504 \\
\hline $\begin{array}{l}\text { Completeness PROM/DHAR \% } \\
(95 \% \mathrm{Cl})\end{array}$ & $\begin{array}{l}56.3 \\
(51.4-61.2)\end{array}$ & $\begin{array}{l}66.7 \\
(63.1-70.3)\end{array}$ & $\begin{array}{l}56.4 \\
(51.9-60.9)\end{array}$ & $\begin{array}{l}64.6 \\
(61.4-67.8)\end{array}$ & $\begin{array}{l}59.8 \\
(56.4-63.2)\end{array}$ & $\begin{array}{l}79.9 \\
(77.0-82.8)\end{array}$ & $\begin{array}{l}89.5 \\
(86.8-92.2)\end{array}$ \\
\hline
\end{tabular}

Abbreviations: DHAR, the Danish hip arthroscopy registry; PROM, patient-reported outcome measure; Cl, confidence interval.

Table 4 Baseline Patient-Reported Outcomes

\begin{tabular}{|c|c|}
\hline & Numbers (\%) or Mean (SD) \\
\hline \multicolumn{2}{|l|}{ Level of physical activity prior to surgery } \\
\hline Sedentary & I363 (4I) \\
\hline Recreational & $1666(50)$ \\
\hline Competitive & $203(6)$ \\
\hline Elite & $110(3)$ \\
\hline General hip status $(0=$ worst, $100=$ best $)$ & $58.6(19.0)$ \\
\hline Hip pain intensity at rest $(0=$ best, $100=$ worst $)$ & $40.0(25.3)$ \\
\hline Hip pain intensity after 15 min. walking $(0=$ best, $100=$ worst $)$ & $51.0(27.3)$ \\
\hline \multicolumn{2}{|l|}{ The Copenhagen hip and groin outcome score } \\
\hline Pain & $48.4(21.8)$ \\
\hline Symptoms & $46.6(20.4)$ \\
\hline Activities of daily living & $49.9(26.0)$ \\
\hline Sports and recreation & $33.3(24.3)$ \\
\hline Physical activity & $20.1(24.9)$ \\
\hline Hip-related quality of life & $28.2(17.6)$ \\
\hline EQ-5D-3L & $0.652(0.188)$ \\
\hline
\end{tabular}

Abbreviation: EQ-5D-3L, European health-related quality of life questionnaire using five dimensions and recording three levels of severity.

males and 55\% females were non-responders versus $45 \%$ males $(\mathrm{p}=0.002)$. A larger proportion of those younger than 25 years had not responded to the one-year followup questionnaire in comparison to the other two age groups $(\mathrm{p}<0.001)$. No difference was observed between responders and non-responders at baseline regarding activity level prior to surgery, although the elite athletes had the highest response rate of $64 \%$. Between responders and non-responders at 1-year follow-up, no differences were observed at baseline for any of the subscales of HAGOS, EQ-5D-3L, or the VAS General Hip status score. No differences were observed between the regions in Denmark between responders and non-responders. Differences in baseline scores between responders and non-responders at 1-year follow-up are presented in Table 5.

\section{Sensitivity Analysis of Surgical Codes Registered in DNPR}

From a total of 5565 total surgeries registered in DNPR, $85.8 \%$ were registered with a primary code from the list provided by the Danish National Board of Health and for the remaining $14.2 \%$ of surgeries, all included a code from the Danish National Board of Health as a secondary code.

\section{Discussion}

Since its inception in 2012, the Danish Hip Arthroscopy Register has steadily improved its completeness rate of registered surgeries versus the total number of hip arthroscopic surgeries performed in Denmark reaching $85 \%$ in 2018 and peaking in 2015 at $94 \%$. The completeness of patients entering data in DHAR in the form of pre-surgical patient characteristics and PROMs has also improved 
Table 5 Baseline Differences Between Responders and Non-Responders at I-Year Follow-Up

\begin{tabular}{|c|c|c|c|c|}
\hline & $\begin{array}{l}\text { Responders } \\
\text { Numbers (\%) }\end{array}$ & $\begin{array}{l}\text { Non-Responders } \\
\text { Numbers (\%) }\end{array}$ & $\begin{array}{l}\text { Difference Between } \\
\text { Groups ( } p \text { value) }\end{array}$ & $\begin{array}{l}\text { Difference Between } \\
\text { Groups }(95 \% \mathrm{Cl})\end{array}$ \\
\hline \multicolumn{5}{|l|}{ Age } \\
\hline$<25$ & $520(18)$ & $495(24)$ & $<0.001$ & \\
\hline $25-39$ & 954 (33) & $693(34)$ & & \\
\hline$\geq 40$ & $1412(49)$ & $875(42)$ & & \\
\hline \multicolumn{5}{|l|}{ Sex } \\
\hline Females & I 707 (59) & $|13|(55)$ & & \\
\hline Males & $1179(4 I)$ & $933(45)$ & 0.002 & \\
\hline \multicolumn{5}{|l|}{$\begin{array}{l}\text { Activity levels prior to } \\
\text { surgery }\end{array}$} \\
\hline Sedentary & $775(4 I)$ & $588(40)$ & & \\
\hline Recreational & $946(50)$ & $720(50)$ & & \\
\hline Competitive & $106(5)$ & $97(7)$ & & \\
\hline \multirow[t]{2}{*}{ Competitive, elite } & $70(4)$ & $40(3)$ & 0.280 & \\
\hline & Mean (SD) & Mean (SD) & & \\
\hline General hip status & $59.2(19.0)$ & $58.2(19.1)$ & 0.170 & $-0.39 I-2.220$ \\
\hline \multicolumn{5}{|l|}{ HAGOS } \\
\hline Pain & $47.7(21.8)$ & $48.9(21.8)$ & 0.120 & $-2.648-0.306$ \\
\hline Symptoms & $46.0(20.4)$ & $47.1(20.3)$ & 0.111 & $-2.507-0.258$ \\
\hline$A D L$ & $49.2(25.8)$ & $50.4(26.0)$ & 0.120 & $-2.999-0.517$ \\
\hline $\begin{array}{l}\text { Sports and } \\
\text { recreation }\end{array}$ & $33.2(24.1)$ & $33.2(24.4)$ & 0.991 & $-1.654-1.635$ \\
\hline Physical activity & $20.9(25.7)$ & $19.5(24.2)$ & 0.105 & $-0.293-3.080$ \\
\hline Hip-related QoL & 28.7 (I7.9) & $27.5(17.3)$ & 0.063 & $-2.323-0.063$ \\
\hline EQ-5D-3L & $0.655(0.185)$ & $0.648(0.192)$ & 0.286 & $-0.020-0.006$ \\
\hline $\begin{array}{l}\text { Hospitals by } \\
\text { geographical region }\end{array}$ & Numbers (\%) & Numbers (\%) & & \\
\hline North Jutland & $238(8)$ & $150(7)$ & & \\
\hline Mid Jutland & $1152(40)$ & $863(42)$ & & \\
\hline Southern Denmark & $393(14)$ & $290(14)$ & & \\
\hline Capitol Region & II03 (38) & 761 (37) & 0.351 & \\
\hline
\end{tabular}

Notes: Proportional differences for categorical data analyzed using chi-squared test and for numerical data, Student's $t$-test (including $95 \%$ confidence intervals) is applied. Abbreviations: Cl, confidence interval; HAGOS, The Copenhagen Hip and Groin Outcome Score; ADL, activities of daily living; QoL, quality of life; EQ-5D-3L, European health-related quality of life questionnaire using five dimensions and recording three levels of severity.

reaching $90 \%$ in 2018 . The percentage of patients returning self-reported questionnaires at 1-year follow-up compared to baseline is currently at $59 \%$. Overall, relevant pre-surgical baseline differences between responders and non-responders at 1-year follow-up demonstrate only differences for the younger population and the males, indicating that data from DHAR are valid and largely generalizable when evaluating 1-year follow-up.

Although the completeness rates for procedure and presurgical PROM registrations in 2017 and 2018 reach a minimum of $80 \%$ and we consider the data from DHAR valid and generalizable, these rates must be continued on a yearly basis and higher rates should be an overall aim. In Denmark, reaching a $90 \%$ completeness rate can qualify a database as a Danish Clinical Quality Database as it has the potential to assist in monitoring clinical quality and patient safety. ${ }^{27}$ It will also qualify for public funding. ${ }^{27}$

To our knowledge, no other national registry has reported completeness of hip arthroscopic surgery at 
procedural level. The non-arthroplasty hip registry (NAHR - United Kingdom) reports data on hip preservation surgery but includes data on both arthroscopy, open hip surgery, peri-acetabular osteotomy, and pediatric hip preservation surgery. ${ }^{28,29}$ Unfortunately, approximately one-third of the pathways (surgeries) are not registered by type. ${ }^{28}$ Surgical information and PROMs are collected pre-surgical and at 6 and 12 months follow-up but not differentiated between type of surgery and no reporting on data quality has been published. For 2018, the percentage of patients completing pre-surgical patient outcomes is $71 \%$ and completion of PROMS at 12 months follow-up is $17 \%$. A regional registry of southern Sweden includes data from two hospitals between November 2011 and January 2013 and pre-surgical patient demographics have been reported. ${ }^{17}$ Completeness of pre-surgical patientreported outcomes is $88 \%$ out of a cohort of 606 patients receiving surgery. No completeness of surgical procedures or data quality is reported. In the state of New York, USA, the Department of Health requires mandatory reporting from all procedures performed in licensed hospitals and record surgical codes and patient demographics. From January 2011 to December 2012, a total of 4602 patients were identified having hip arthroscopy and 3957 had complete data. ${ }^{30}$ No PROMs are collected and data quality is not recorded.

In comparison to our findings, the mean age at operation across the above studies is very similar ranging from 36 to 38 with an SD of 13 and a range of 9 to 80 years of age. ${ }^{17,30,31}$ This is in contrast to the common belief of hip arthroscopy being for the young and active population and several studies indicate poorer outcomes of hip arthroscopy for the middle age and older population. ${ }^{32,33}$ The ratio of women undergoing arthroscopic surgery is in our study very similar to the population in the United Kingdom and in the state of New York with a combined range of 55-60\% but distinctly different from the Swedish cohort where two-thirds are males. The difference could be due to the relatively smaller numbers in the Swedish study ( $\mathrm{n}=606)$ or related to a cultural difference between surgeons in different countries. Particularly the morphological changes of cam and associated with femoro-acetabular impingement syndrome are predominantly more common in males and younger individuals participating in sports at elite and high competitive levels. ${ }^{34}$

In comparison to other national orthopedic registries in Denmark and the other Scandinavian countries, completeness in DHAR is comparable. For primary total hip arthroplasty in Denmark, the highest completeness rate of $98 \%$ was reached in 2014 and $92 \%$ for revision hip arthroplasty, also using the DNPR as reference. ${ }^{35}$ The Norwegian Arthroplasty Register reports a completeness rate of $98 \%$ for hip arthroplasties (2002) and the Swedish National Total Hip Arthroplasty Register report completeness of $95 \%$ of all total hip arthroplasties operated in Sweden in $1994 .{ }^{36}$

The Danish Knee Ligament Reconstruction Registry (DKRR) reports completeness of $86 \%$ (2011) using the same referencing DNPR standards as our study ${ }^{7}$ and the 1-year clinical/surgical follow-up rate for patients operated in 2012 was $45 \%$. Only $33 \%$ of patients completed presurgical outcome measures and the 1-year follow-up rate of patient-reported outcome measures was $27 \%$. The markedly lower completion rate by patients is commonly seen in large registries but it appears the rate in DHAR is higher when compared to other studies. ${ }^{7}$

\section{Strengths and Limitations}

Our study includes a number of strengths. First, every hospital in Denmark performing hip arthroscopies provides data to DHAR making it a truly national database from every hospital performing the operation. Second, even being a new registry, completeness has improved to a level of more than $90 \%$ both for the number of all hip arthroscopies performed in Denmark and the ratio of completed pre-surgical patient outcome measures from an apparent unselected patient population. Third, due to the unique CPR number, any national clinical database in Denmark/Scandinavia has the potential for cross-referencing to other databases related to relevant health and/or social variables.

We have identified the following limitations: First, although no major pre-surgical patient characteristics were different between the responders and nonresponders, we are naturally not able to assess the outcome of the surgery for the group of non-responders and interpretation of outcome studies using the DHAR is likely prone to selection bias. Secondly, in Denmark, the DNPR is commonly used as the referencing standard when quality assessing specialty-specific registries. However, we were able to identify 23 surgeries registered in DHAR not registered in DNPR. This difference could be due to hospitals receiving direct payment from patients without involvement of insurance or public funding as no incentive is then in place for registering the patient in DNPR. Thirdly, during the identification of surgical codes used for hip arthroscopy in the DNPR, we have observed a lack of consensus between surgeons and hospitals performing hip arthroscopies. This is likely influencing the 
identification of the exact number of surgeries performed in Denmark. Unfortunately, we have no way of assessing this possible discrepancy. Lastly, we have not had access to hospital medical records or diagnostic imaging and therefore, have not been able to estimate predictive values for a pre-specified diagnosis or possible surgical complications.

\section{Conclusion}

Completeness in the form of surgeries registered in the Danish hip arthroscopy register and patients reporting presurgical outcomes has steadily improved since its inception in 2012 passing $90 \%$ in 2015 for surgical registration and in 2018 for PROMs. The 1-year follow-up reporting by the patients is currently at $60 \%$; however, our current evaluation indicates no major differences exist at presurgical level between responders and non-responders for PROMs. Efforts for improving the patient reporting at 1 -year are recommended with a focus on the age group below 25 years and for the male population. Lastly, we recommend standardization of surgical codes for registration of hip arthroscopic surgery in the Danish National Patient Registry.

\section{Abbreviations}

DHAR, Danish hip arthroscopy registry; DNPR, Danish national patient registry; PROM, patient-reported outcome measures; HSAS, hip sports activity scale; HAGOS, The Copenhagen hip and groin outcome score; VAS, visual analogue scale; EQ-5D-3L, European health-related quality of life questionnaire using five dimensions and recording 3 levels of severity; NAHR, non-arthroplasty hip registry.

\section{Ethics Approval and Informed Consent}

Prior to entering information into DHAR, patients give written consent to the use of data for research purposes. This project is approved by the National Board of Health and the Danish Data Protection Agency, journal number 2015-41-4278.

\section{Author Contributions}

All authors contributed to data analysis, drafting or revising the article, have agreed on the journal to which the article will be submitted, gave final approval of the version to be published, and agree to be accountable for all aspects of the work.

\section{Funding}

The study was funded by IMK Almene Fond.

\section{Disclosure}

$\mathrm{BL}$ is the administrator and part of the steering committee of the Danish Hip Arthroscopy Registry. ER is the deputy editor of Osteoarthritis and Cartilage, the developer of Knee injury and Osteoarthritis Outcome Score (KOOS) and several other freely available patient-reported outcome measures and founder of the Good Life with Osteoarthritis in Denmark (GLA:D), a not-for-profit initiative to implement clinical guidelines in primary care. The authors report no other conflicts of interest in this work.

\section{References}

1. Griffin DR, Dickenson EJ, O'Donnell J, et al. The Warwick agreement on femoroacetabular impingement syndrome (FAI syndrome): an international consensus statement. $B r \quad J \quad$ Sports $\quad$ Med. 2016;50 (19):1169-1176. doi:10.1136/bjsports-2016-096743

2. Maradit Kremers H, Schilz SR, Van Houten HK, et al. Trends in utilization and outcomes of hip arthroscopy in the United States between 2005 and 2013. J Arthroplasty. 2017;32(3):750-755. doi:10.1016/j.arth.2016.09.004

3. Bonazza NA, Homcha B, Liu G, Leslie DL, Dhawan A. Surgical trends in arthroscopic hip surgery using a large national database. Arthroscopy. 2018;34(6):1825-1830. doi:10.1016/j.arthro.2018.01.022

4. Palmer AJ, Malak TT, Broomfield J, et al. Past and projected temporal trends in arthroscopic hip surgery in England between 2002 and 2013. BMJ Open Sport Exerc Med. 2016;2(1):e000082. doi:10.1136/ bmjsem-2015-000082

5. Lee YK, Ha YC, Yoon BH, Koo KH. National trends of hip arthroscopy in Korea. J Korean Med Sci. 2014;29(2):277-280. doi:10.3346/ jkms.2014.29.2.277

6. Ohlin A, Karlsson L, Senorski EH, et al. Quality assessment of prospective cohort studies evaluating arthroscopic treatment for femoroacetabular impingement syndrome: a systematic review. Orthop $J$ Sports Med. 2019;7(5):2325967119838533. doi:10.1177/ 2325967119838533

7. Rahr-Wagner L, Thillemann TM, Lind MC, Pedersen AB. Validation of 14,500 operated knees registered in the Danish Knee Ligament Reconstruction Register: registration completeness and validity of key variables. Clin Epidemiol. 2013;5:219-228. doi:10.2147/CLEP. S45752

8. Pedersen A, Johnsen S, Overgaard S, Soballe K, Sorensen HT, Lucht U. Registration in the danish hip arthroplasty registry: completeness of total hip arthroplasties and positive predictive value of registered diagnosis and postoperative complications. Acta Orthop Scand. 2004;75(4):434-441. doi:10.1080/00016470410001213-1

9. Arthursson AJ, Furnes O, Espehaug B, Havelin LI, Soreide JA. Validation of data in the Norwegian Arthroplasty Register and the Norwegian Patient Register: 5134 primary total hip arthroplasties and revisions operated at a single hospital between 1987 and 2003. Acta Orthop. 2005;76(6):823-828. doi:10.1080/17453670510045435

10. Lund B. Dansk Hofte Artroskopi Register - DHAR. Arsrapport 2012 (The Danish Hip Arthroscopy Registry - DHAR. Annual Report 2012). Danmark: Aarhus Universitetshospital 2013.

11. Lund B, Kraemer O, Hölmich P, Maagaard N, Winge S. Dansk Hofte Arthroskopi Register - DHAR. Arsrapport 2016. (The Danish Hip Arthroscopy Registry - DHAR. Annual Report 2016). Danmark: Horsens Regionshospital 2017. 
12. Sorensen HT. Regional administrative health registries as a resource in clinical epidemiology. A study of options, strengths, limitations and data quality provided with examples of use. Int J Risk Saf Med. 1997;10(1):1-22. doi:10.3233/JRS-1997-10101

13. Sorensen HT, Sabroe S, Olsen J. A framework for evaluation of secondary data sources for epidemiological research. Int J Epidemiol. 1996;25(2):435-442. doi:10.1093/ije/25.2.435

14. Schmidt M, Schmidt SAJ, Adelborg K, et al. The Danish health care system and epidemiological research: from health care contacts to database records. Clin Epidemiol. 2019;11:563-591. doi:10.2147/ CLEP.S179083

15. Skou ST, Roos EM. Good Life with osteoArthritis in Denmark (GLA D): evidence-based education and supervised neuromuscular exercise delivered by certified physiotherapists nationwide. BMC Musculoskelet Disord. 2017;18(1):72. doi:10.1186/s12891-017-1439-y

16. Polk A, Rasmussen JV, Brorson S, Olsen BS. Reliability of patient-reported functional outcome in a joint replacement registry. A comparison of primary responders and non-responders in the Danish Shoulder Arthroplasty Registry. Acta Orthop. 2013;84 (1):12-17. doi:10.3109/17453674.2013.765622

17. Sansone M, Ahlden M, Jonasson P, et al. A Swedish hip arthroscopy registry: demographics and development. Knee Surg Sports Traumatol Arthrosc. 2014;22(4):774-780. doi:10.1007/s00167-014-2840-9

18. Mygind-Klavsen B, Gronbech Nielsen T, Maagaard N, et al. Danish Hip Arthroscopy Registry: an epidemiologic and perioperative description of the first 2000 procedures. J Hip Preserv Surg. 2016;3 (2):138-145. doi:10.1093/jhps/hnw004

19. Thorborg K, Holmich P, Christensen R, Petersen J, Roos EM. The Copenhagen Hip and Groin Outcome Score (HAGOS): development and validation according to the COSMIN checklist. Br J Sports Med. 2011;45(6):478-491. doi:10.1136/bjsm.2010.080937

20. Griffin DR, Parsons N, Mohtadi NG, Safran MR. A short version of the International Hip Outcome Tool (iHOT-12) for use in routine clinical practice. Arthroscopy. 2012;28(5):611-616. doi:10.1016/j. arthro.2012.02.027

21. Sorensen J, Davidsen M, Gudex C, Pedersen KM, Bronnum-Hansen H. Danish EQ-5D population norms. Scand J Public Health. 2009;37 (5):467-474. doi:10.1177/1403494809105286

22. Naal FD, Miozzari HH, Kelly BT, Magennis EM, Leunig M, Noetzli HP. The Hip Sports Activity Scale (HSAS) for patients with femoroacetabular impingement. HIP Int. 2013;23(2):204-211. doi:10.5301/hipint.5000006

23. Lynge E, Sandegaard JL, Rebolj M. The Danish National Patient Register. Scand J Public Health. 2011;39(7 Suppl):30-33. doi:10.1177/1403494811401482
24. Pedersen CB. The Danish Civil Registration System. Scand J Public Health. 2011;39(7_suppl):22-25. doi:10.1177/1403494810387965

25. The Danish Health Authority. Specialevejledning for Ortopcedisk Kirurgi. København: Sundhedsstyrelsen; March 2018:1-19

26. The Danish Health Authority. Specialevejledning for Ortopcedisk Kirurgi. København: Sundhedsstyrelsen; July 2012:1-17

27. Sorensen HT, Pedersen L, Jorgensen J, Ehrenstein V. Danish Clinical Quality Databases - an important and untapped resource for clinical research. Clin Epidemiol. 2016;8:425-427. doi:10.2147/CLEP.S113265

28. The British Hip Society. Non-Arthroplasty Hip Registry, 4th Annual Report 2019. London, United Kingdom: Royal College of Surgeons of England 2020.

29. Humphrey JA, George MD, Bankes MJK. Experience and outcome data of the British non-arthroplasty hip registry. Hip Int. 2018;28 (4):429-433. doi:10.5301/hipint.5000594

30. Kester BS, Capogna B, Mahure SA, Ryan MK, Mollon B, Youm T. Independent risk factors for revision surgery or conversion to total hip arthroplasty after hip arthroscopy: a review of a large statewide database from 2011 to 2012. Arthroscopy. 2018;34(2):464-470. doi:10.1016/j.arthro.2017.08.297

31. Malviya A, Raza A, Jameson S, James P, Reed MR, Partington PF. Complications and survival analyses of hip arthroscopies performed in the national health service in England: a review of 6395 cases. Arthroscopy. 2015;31(5):836-842. doi:10.1016/j.arthro.2014.12.013

32. Lieberman JR. Hip arthroscopy for femoroacetabular impingement patients older than 50 years-proceed with caution. Arthroscopy. 2019;35(9):2759-2760. doi:10.1016/j.arthro.2019.07.002

33. Sogbein OA, Shah A, Kay J, et al. Predictors of outcomes after hip arthroscopic surgery for femoroacetabular impingement: a systematic review. Orthop J Sports Med. 2019;7(6):2325967119848982. doi:10.1177/2325967119886591

34. Dickenson E, Wall PD, Robinson B, et al. Prevalence of cam hip shape morphology: a systematic review. Osteoarthritis Cartilage. 2016;24(6):949-961. doi:10.1016/j.joca.2015.12.020

35. Gundtoft PH, Varnum C, Pedersen AB, Overgaard S. The Danish Hip Arthroplasty Register. Clin Epidemiol. 2016;8:509-514. doi:10.2147/ CLEP.S99498

36. Soderman P, Malchau H, Herberts P, Johnell O. Are the findings in the Swedish National Total Hip Arthroplasty Register valid? A comparison between the Swedish National Total Hip Arthroplasty Register, the National Discharge Register, and the National Death Register. J Arthroplasty. 2000;15(7):884-889. doi:10.1054/arth.2000.8591
Clinical Epidemiology

\section{Publish your work in this journal}

Clinical Epidemiology is an international, peer-reviewed, open access, online journal focusing on disease and drug epidemiology, identification of risk factors and screening procedures to develop optimal preventative initiatives and programs. Specific topics include: diagnosis, prognosis, treatment, screening, prevention, risk factor modification,

Submit your manuscript here: https://www.dovepress.com/clinical-epidemiology-journal systematic reviews, risk \& safety of medical interventions, epidemiology \& biostatistical methods, and evaluation of guidelines, translational medicine, health policies \& economic evaluations. The manuscript management system is completely online and includes a very quick and fair peer-review system, which is all easy to use. 